\title{
The developmental venous anomaly associated with the cavernous malformation
}

\author{
Svjetlana Mujagić, Jasmina Bećirović Ibrišević
}

Department of Radiology and Nuclear Medicine, University Clinical Center Tuzla

Tuzla, Bosnia and Herzegovina

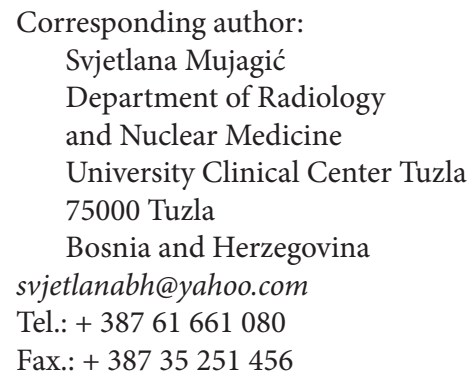

Received: 8 January 2012

Accepted: 9 April 2012

\section{Copyright (c) 2012 by}

Academy of Sciences and Arts

of Bosnia and Herzegovina.

E-mail for permission to publish:

amabih@anubih.ba

A magnetic resonance imaging (MRI) study was ordered in a 32-year-old man with a 6 month history of double vision and confirmed left abducens nerve palsy on neurological examination. Non-enhanced T1 and T2-weighted images revealed the presence of a cavernous malformation (CM) in the left lateral aspect of the mesencephalon (mostly in the left inferior colliculus), asso- ciated with a large blood vessel in the close vicinity of the $\mathrm{CM}$, which corresponded to the collector vein of the developmental venous anomaly (DVA), also known as venous angioma (Figure A, B). The contrast-enhanced T1-weighted images showed small dilated medullary veins of the DVA in both cerebellar hemispheres and a large collector vein draining toward the deep venous system, also visualised on non-enhanced images (Figure $C, D$ ). The neurosurgeon suggested neuro-radiological follow-up. The prevalence of DVAs associated with CM can be underestimated even when high field MR is used. Based on MR imaging and intraoperative findings, Wurm et al. identified 25.9\% patients with CM who had associated DVA (1). Although CMs have a relatively benign nature, surgery may be recommended when they become symptomatic (most frequently associated with seizures, less frequently with neurological deficit), or if bleeding occurs. In the present case we did not found evidence of recent intracerebellar bleeding. When surgical intervention is ordered and if the DVA is in a close vicinity to the CM, the DVA should be spared in order to prevent the development of venous infarction due to resection of the main collector vein (2). Contrast-enhanced MRI has the most important role in detection of a DVA associated with a CM, since it may be invisible on non-enhanced MRI. 

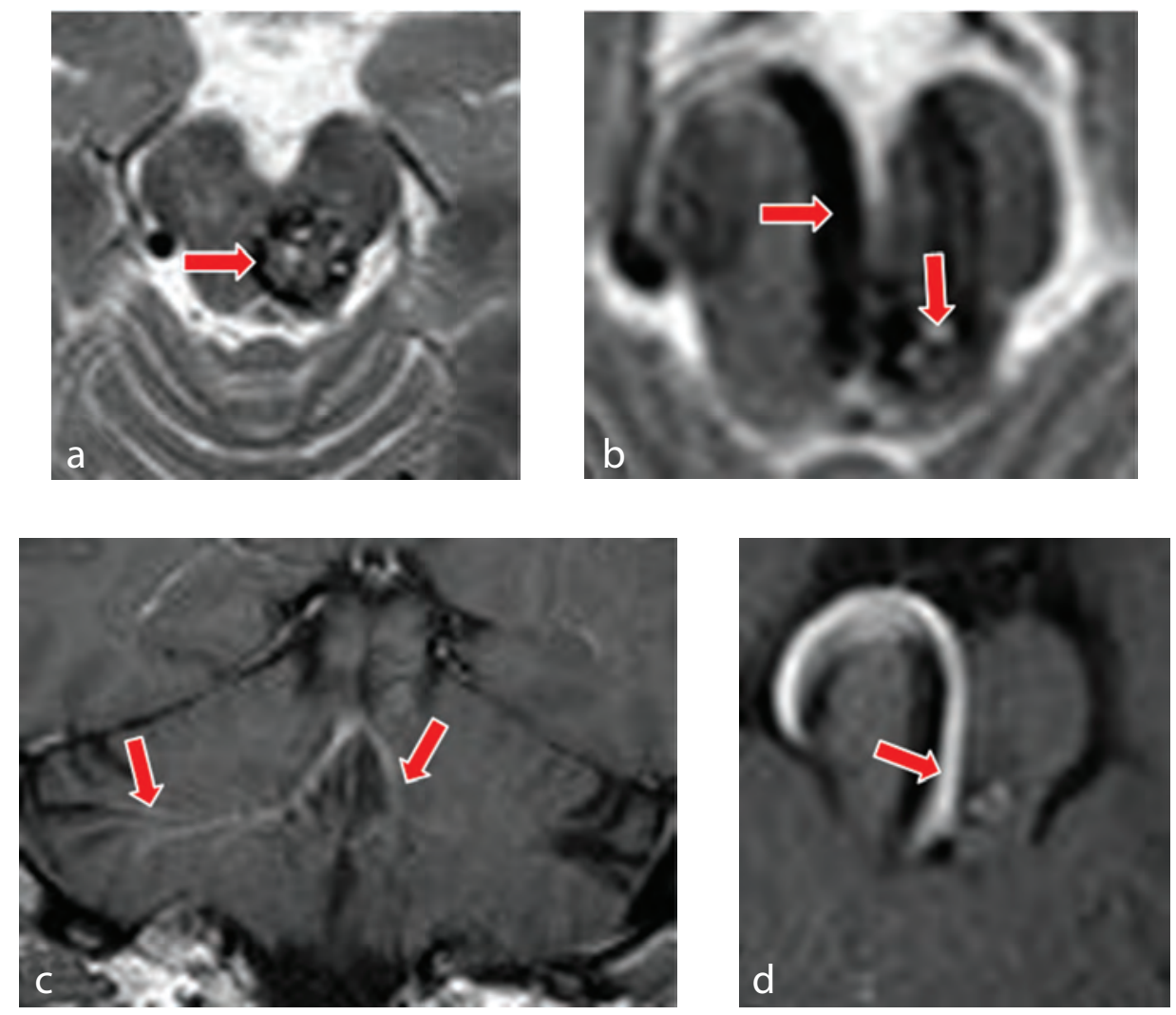

Authors' contributions: Conception and design: SM; Acquisition, analysis and interpretation of data: SM and BIJ; Drafting the article SM; Revising it critically for important intellectual content: SM.

Conflict of interest: The authors declare that they have no conflict of interest. This study was not sponsored by any external organisation.

\section{References}

1. Wurm G, Schnizer M, Nussbaumer K, Wies W, Holl K. Recurrent cryptic vascular malformation associated with a developmental venous anomaly. Br J Neurosurg. 2003;17:188-95.

2. Perrini P, Lanzino G. The association of venous developmental anomalies and cavernous malformations: pathophysiological, diagnostic, and surgical considerations. Neurosurg Focus. 2006;21(1):e5. 